\title{
High Performance Quantum Cascade Lasers Based on Three-Phononresonance Design
}

\section{Citation}

Wang,Qi Jie, Christian Pflügl, Laurent Diehl, Federico Capasso, Tadataka Edamura, Shinichi Furuta, Masamichi Yamanishi, Hirofumi Kan. 2009. High performance quantum cascade lasers based on three-phononresonance design. Applied Physics Letters 94(1): 011103.

\section{Published Version}

doi:10.1063/1.3062981

\section{Permanent link}

http://nrs.harvard.edu/urn-3:HUL.InstRepos:3445986

\section{Terms of Use}

This article was downloaded from Harvard University's DASH repository, and is made available under the terms and conditions applicable to Other Posted Material, as set forth at http:// nrs.harvard.edu/urn-3:HUL.InstRepos:dash.current.terms-of-use\#LAA

\section{Share Your Story}

The Harvard community has made this article openly available.

Please share how this access benefits you. Submit a story.

Accessibility 


\title{
High performance quantum cascade lasers based on three-phonon- resonance design
}

\author{
Qi Jie Wang, ${ }^{1, a)}$ Christian Pflügl, ${ }^{1}$ Laurent Diehl, ${ }^{1}$ Federico Capasso, $\left.{ }^{1, b}\right)$ \\ Tadataka Edamura, ${ }^{2}$ Shinichi Furuta, ${ }^{2}$ Masamichi Yamanishi, ${ }^{2}$ and Hirofumi $\mathrm{Kan}^{2}$ \\ ${ }^{1}$ School of Engineering and Applied Sciences, Harvard University, Cambridge, Massachusetts 02138, USA \\ ${ }^{2}$ Central Research Laboratories, Hamamatsu Photonics K. K., Shizuoka 434-8601, Japan
}

(Received 10 November 2008; accepted 10 December 2008; published online 6 January 2009)

\begin{abstract}
A quantum cascade laser structure based on three-phonon-resonance design is proposed and demonstrated. Devices, emitting at a wavelength of $9 \mu \mathrm{m}$, processed into buried ridge waveguide structures with a $3 \mathrm{~mm}$ long, $16 \mu \mathrm{m}$ wide cavity and a high-reflection (HR) coating have shown peak output powers of $1.2 \mathrm{~W}$, slope efficiencies of $1 \mathrm{~W} / \mathrm{A}$, threshold current densities of $1.1 \mathrm{kA} / \mathrm{cm}^{2}$, and high wall-plug efficiency of $6 \%$ at $300 \mathrm{~K}$. A $3 \mathrm{~mm}$ long, $12 \mu \mathrm{m}$ wide buried-heterostructure device without a HR coating exhibited continuous wave output power of as high as $65 \mathrm{~mW}$ from a single facet at $300 \mathrm{~K}$. () 2009 American Institute of Physics.
\end{abstract}

[DOI: $10.1063 / 1.3062981]$

Quantum cascade lasers (QCLs) can be designed and fabricated to cover the whole midinfrared range $(3-25 \mu \mathrm{m})$, which is important for gas analysis and chemical sensing, industrial process monitoring, free-space communication, and military applications. Due to their small footprint, their high performance at room temperature (RT), and the possibility to easily tailor their emission wavelength, QCLs are the most convenient light sources in the midinfrared. QCLs with state-of-the-art performance can be grown using either molecular beam epitaxy (MBE) or metal organic vapor phase epitaxy (MOVPE).

Since the invention of QCLs in 1994, ${ }^{1}$ tremendous progress has been made to improve the performance of QCLs, leading to the demonstration of continuous wave $(\mathrm{cw})$ output powers exceeding $1 \mathrm{~W}$ at $4.6 \mu \mathrm{m},{ }^{2,3} 200 \mathrm{~mW}$ at $8 \mu \mathrm{m},{ }^{4}$ and $100 \mathrm{~mW}$ at $10 \mu \mathrm{m}$ (Ref. 5) at RT. These were achieved by rapid advances in material growth, processing technology, waveguide design and packaging, and last but not least by constant improvements in the band-structure design of the QCL gain medium. Because of the huge parameter space available in the band-structure design, a wide variety of designs has been demonstrated, including, for example, active regions based on a two-phonon resonance, ${ }^{2,6}$ on a bound-to-continuum design, ${ }^{7}$ on a chirped superlattice, ${ }^{8}$ and on a single-phonon-continuum design. ${ }^{9}$

To ensure a large population inversion in QCLs, efficient injection of electrons into the upper laser level and fast depletion of the lower laser level are essential. In this letter, we focus on the depletion scheme in QCLs and propose an improved active region and injector region structure based on longitudinal optical (LO) phonon scattering, which is known to be the fastest intersubband relaxation process. The first QCL (Ref. 1) was based on a one-phonon depopulation scheme making use of the efficient phonon scattering between two electronic subbands. In this active region design, electrons relax from the lower laser level into the active region ground state by LO-phonon emission. If the energy spacing between the two states is equal to or slightly larger

\footnotetext{
${ }^{a)}$ Electronic mail: qijie@seas.harvard.edu.

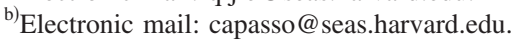

than the LO-phonon energy $\left(E_{\mathrm{LO}}\right)$, very short lifetimes $(\sim 0.2 \mathrm{ps})$ for the lower laser level are assumed. However, it was found ${ }^{10,11}$ that due to the relatively long escape times $(\sim 2-3 \mathrm{ps})$ from the active region into the injector region, electrons accumulate in the active region ground state. This significantly increases the effective lifetime of the lower laser level due to thermally activated backfilling of the electrons from the active region ground state into the lower laser level. Based on these findings, the so-called two-phononresonance design was proposed and demonstrated. ${ }^{12}$ In this design, the enhanced relaxation rate out of the lower laser level is obtained by a ladder of three lower energy states spaced by an optical phonon each in the active region, leading to very short effective lifetimes. The energy separation between the active region ground state and the lower laser level is increased, which decreases thermal backfilling of the electrons from the active region ground state. Since the first demonstration of the two-phonon design, all high performance cw QCLs working at high temperatures were based on this concept.

According to the calculations in Ref. 11, it appears, however, that there are still a non-negligible number of electrons in the lower laser level. Thus, we propose an active region design based on a three-phonon-resonance scheme to more efficiently deplete the lower laser level. We performed simulations based on the rate equation model discussed in Ref. 11, and the results of our calculations show that the ratio between the electron population in the lower laser level and in the upper laser level $\eta$ is $\sim 0.22$ at RT for the proposed three-phonon structure (see Fig. 1) compared to $\sim 0.35$ reported for two-phonon designs. ${ }^{11}$ This can be expressed in the calculation of an effective lower state lifetime $\tau_{l}^{\text {eff }}=\eta \tau_{u}{ }^{11}$ where $\tau_{u}$ is the upper laser lifetime. Note that $\eta$ includes tunneling rates from the lower energy levels of the active region to the energy levels in the injector region. Thus, the effective lower state lifetime for the three-phonon design has a reduced value of $0.14 \mathrm{ps}$ in comparison to $0.23 \mathrm{ps}$ of the two-phonon design based on our calculation. In addition to the more efficient LO-phonon based depletion scheme proposed, four states (levels $4^{\prime}, 3^{\prime}, 2^{\prime}$, and $1^{\prime}$ ) from the injector region are designed to couple to the four active region states 


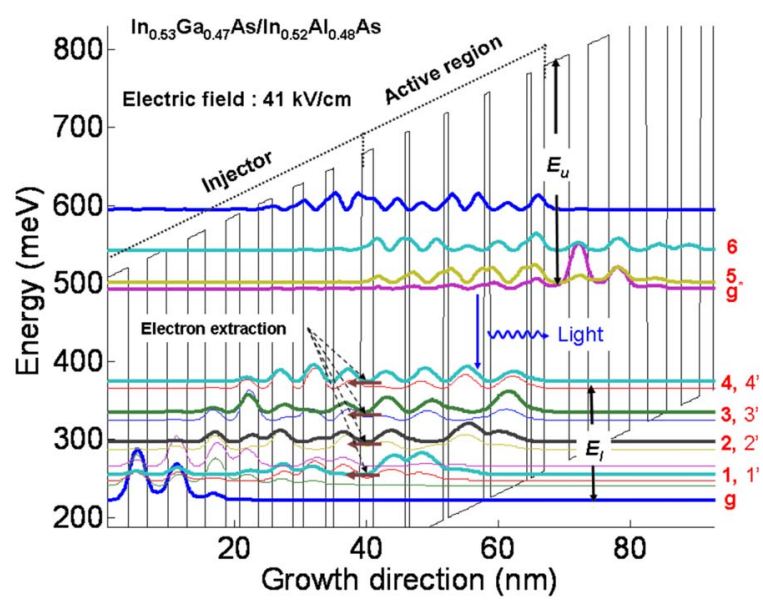

FIG. 1. (Color online) Conduction band diagram of the three-phononresonance active region design under an applied electric field of $41 \mathrm{kV} / \mathrm{cm}$. The designed emission wavelength is around $9.4 \mu \mathrm{m}$ at RT, between levels 5 and $\left(4,4^{\prime}\right)$. The layer sequence of one period (in nanometer), starting from the injection barrier is 3.8/1.9/0.7/5.6/0.8/5.5/0.8/5.1/0.7/4.8/2.0/4.0/1.2/3.5/ 1.5/3.2/2.0/2.9/2.1/3.1/2.7/3.1/3.1/2.9, where $\mathrm{In}_{0.52} \mathrm{Al}_{0.48} \mathrm{As}$ layers are in bold and the underlined numbers correspond to the doped layers (Si, $2 \times 10^{17} \mathrm{~cm}^{-3}$ ).

(levels 4, 3, 2, and 1), respectively, with an average energy splitting of $\sim 9 \mathrm{meV}$, as shown in Fig. 1. Thus, electrons can resonantly tunnel from all of these lower active region states efficiently into the injector region. The injector design also makes use of resonant LO-phonon scattering to ensure fast relaxation of electrons down to the ground state of the injector, from which electrons are then injected into the upper laser level of the following stage through resonant tunneling. In the proposed three-phonon design, the spacing between the upper laser level (level 5) and the state above (level 6) $(\sim 40 \mathrm{meV})$ is lower than in most other designs (more than $50 \mathrm{meV}$ ). According to our rate equation analysis, however, we expect similar injection efficiency into the upper laser level (level 5). The spacing between level 5 and level 6 is only slightly larger than the LO-phonon energy, thus electrons injected into level 6 are quickly $(\sim 0.26 \mathrm{ps})$ scattered into the upper laser level 5.

Although the insertion of energy levels in the active region to increase the number of LO-phonon resonances to efficiently deplete the lower laser level is a straightforward approach, it is limited by other design requirements in QC active regions. The introduction of resonances would shift the upper laser state closer to the continuum increasing leakage current paths, and it would also increase the defect voltage. Thus the optimum number of resonances depends on many different factors and is different, e.g., for different material systems and/or wavelength regions. The structure presented in this letter is based on the InGaAs/InAlAs material system latticed matched to InP. (Detailed layer sequence is given in the caption of Fig. 2.) The calculated emission wavelength (from energy level 5 to levels 4 and $4^{\prime}$ ) is 9.4 $\mu \mathrm{m}$ at RT. The dipole matrix element of the laser transition $(3.5 \mathrm{~nm})$ is increased compared to two-phonon designs [3 $\mathrm{nm}$ (Ref. 11)] because of the use of five quantum wells in the active region and a vertical transition design, which increases the spatial overlap of the laser transition levels. The calculated upper state lifetime $\tau_{5}$ and the scattering time from the upper laser level to the lower laser level $\tau_{54}$ at 300 $\mathrm{K}$ are 0.62 and $2.3 \mathrm{ps}$, respectively, compared to 0.66 and 1.8

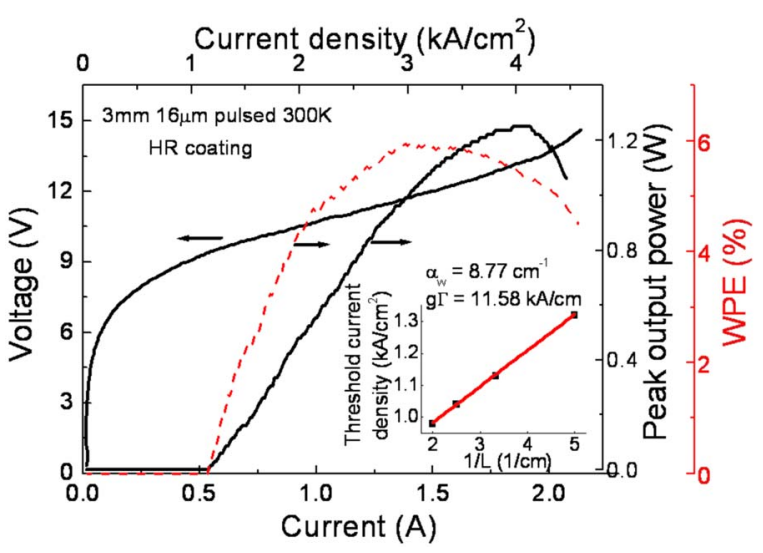

FIG. 2. (Color online) Light output power vs current $(L-I)$ and voltage vs current $(V-I)$ (solid line) curves in pulsed operation and WPE (WPE: dashed line) measured at a sink temperature of $300 \mathrm{~K}$, for a $3 \mathrm{~mm}$ long HR coated QC laser with a ridge width of $16 \mu \mathrm{m}$. The threshold current density of this device is about $1.1 \mathrm{kA} / \mathrm{cm}^{2}$ and the current density at roll over is about $4.0 \mathrm{kA} / \mathrm{cm}^{2}$. The inset shows the pulsed threshold current densities of $12 \mu \mathrm{m}$ wide devices of various cavity lengths without HR coating.

ps, respectively, for two-phonon designs. ${ }^{11}$ The energy separation between levels 1 and 4 is $116 \mathrm{meV}$ at resonance. The energy separation of $E_{l}$ (Fig. 2) is important to reduce thermal activated backfilling from the injector ground state. In our structure, $E_{l}$ is designed to be $153 \mathrm{meV}$ at the resonance condition. The energy separation of $E_{u}$ (Fig. 1), which is important to suppress carrier leakage into the continuum, is $238 \mathrm{meV}$ in our case in comparison with $244 \mathrm{meV}$ for twophonon designs ${ }^{6}$ at the resonance condition. This parasitic leakage path to the continuum is expected to have the same negative impact on the performance of two-phonon and three-phonon structures since the value of $E_{u}$ is essentially the same in both designs.

The structure was grown on a $n$-doped InP substrate $\left(\sim 3 \times 10^{18} \mathrm{~cm}^{-3}\right)$, starting with a $3.5 \mu \mathrm{m}$ thick $n$-doped $\left(3 \times 10^{16} \mathrm{~cm}^{-3}\right)$ InP layer, followed by a $200 \mathrm{~nm}$ thick $n$-doped $\left(3 \times 10^{16} \mathrm{~cm}^{-3}\right)$ InGaAs layer, the active region, a $200 \mathrm{~nm}$ thick $n$-doped $\left(3 \times 10^{16} \mathrm{~cm}^{-3}\right)$ InGaAs layer, and a top waveguide cladding [consisting of a $3.5 \mu \mathrm{m}$ thick $n$-doped $\left(3 \times 10^{16} \mathrm{~cm}^{-3}\right)$ InP layer, a $1 \mu \mathrm{m}$ thick $n$-doped $\left(3 \times 10^{18} \mathrm{~cm}^{-3}\right)$ InP layer, and a thin $20 \mathrm{~nm}$ highly $n$-doped $\left(1 \times 10^{19} \mathrm{~cm}^{-3}\right)$ InGaAs contact layer]. The active region consists of 40 stages of lattice matched $\mathrm{In}_{0.53} \mathrm{Ga}_{0.47} \mathrm{AS} / \mathrm{In}_{0.52} \mathrm{Al}_{0.48} \mathrm{As}$ well and barrier layers, grown by MBE. The top InP and InGaAs waveguide layers were grown by MOVPE. The samples were processed into 12, 16, and $20 \mu \mathrm{m}$ wide buried-heterostructure lasers defined by dry etching. A thick Fe-doped InP layer was regrown by MOVPE. After metallization of the top contacts with $\mathrm{Ti} / \mathrm{Au}$, the devices were electroplated with about $10 \mu \mathrm{m}$ thick $\mathrm{Au}$ on the top surface. The wafer was then thinned down to $150 \mu \mathrm{m}$, and a Ge/Au $(10 \mathrm{~nm} / 200 \mathrm{~nm})$ bottom contact was deposited by e-beam evaporation. Laser bars with different lengths were cleaved and soldered epilayer up on copper submounts with Indium for pulsed operation measurement. Some of the devices were high-reflection (HR) coated on the back facet using $\mathrm{Al}_{2} \mathrm{O}_{3} / \mathrm{Ti} / \mathrm{Au}(200 \mathrm{~nm} / 10 \mathrm{~nm} / 150 \mathrm{~nm})$ via e-beam evaporation.

Figure 2 shows the light-current-voltage ( $L I V)$ characteristics of a HR coated $16 \mu \mathrm{m}$ wide, $3 \mathrm{~mm}$ long device operated in pulsed mode (pulse width $100 \mathrm{~ns}$ and $20 \mathrm{kHz}$ repeti- 
tion rate) at a heat sink temperature of $300 \mathrm{~K}$. The maximum output power is $1.2 \mathrm{~W}$ in pulsed operation with a low threshold current density of $1.1 \mathrm{kA} / \mathrm{cm}^{2}$. The slope efficiency of this device is around 1.05 W/A at $300 \mathrm{~K}$, and the measured maximum wall-plug efficiency (WPE) of the device operated in pulsed mode is around 6\%. The previously reported QCL (Ref. 13) at $\lambda=9 \mu \mathrm{m}$ in pulsed operation had a slope efficiency of $\sim 700 \mathrm{~mW} / \mathrm{A}$ and a WPE of $\sim 3 \%$. High output powers can always be reached by increasing the doping in the active region; however this usually also leads to an increase in threshold current density due to free carrier absorption. It should be noted that our devices still have very low threshold current densities at RT despite their high roll-over current density. Waveguide losses and modal gain coefficient were deduced from the measurements of the threshold current densities of devices with different cavity lengths. Devices with $12 \mu \mathrm{m}$ wide ridges with different lengths of 2,3 , 4 , and $5 \mathrm{~mm}$, without HR coatings, were used. As shown in the inset of Fig. 2, a linear least-squares fit to the measured values gives a modal gain coefficient $g \Gamma$ of $11.58 \mathrm{~cm} / \mathrm{kA}$ and a total waveguide loss $\alpha_{w}$ of $8.77 \mathrm{~cm}^{-1}$, where $g$ is the gain coefficient and $\Gamma$ is the optical confinement factor. The experimentally obtained value for the modal gain coefficient is about 20\% larger than the ones reported for the two-phonon design in Ref. 5, even though in our case $\Gamma$ is smaller because 40 active region cascades instead of 50 were used. The decrease in $\Gamma$ is more than compensated by the increase in the material gain due to the larger dipole matrix element and shorter effective lifetime of the lower laser level of the threephonon design. Based on the calculated dipole matrix elements and lifetimes, we estimated that the gain coefficient $g$ of the three-phonon-resonance design increases by around $23 \%$ compared to gain coefficients reported for two-phonon designs, ${ }^{11}$ assuming the same full width at half maximum of the luminescence spectrum, in good agreement with the experimental observations.

For cw measurement, lasers mounted epilayer down on copper plates were attached to a temperature controlled thermoelectric (TE) cooler. A calibrated thermopile detector was placed close to the laser emitting facet to measure the output power of one facet of the laser. Figure 3 shows the LIV characteristics of a $12 \mu \mathrm{m}$ wide, $3 \mathrm{~mm}$ long device without HR coating operated in $\mathrm{cw}$ mode at various heat sink temperatures. The maximum output power of the device reaches about $65 \mathrm{~mW}$ measured from a single facet at $300 \mathrm{~K}$, and it is not corrected for an estimated $70 \%$ collection efficiency of the setup. The device has a maximum cw WPE of around $1.4 \%$ at RT considering the output power from both facets. Although a direct comparison with recent results is difficult, as doping levels, waveguide design, and packaging, etc., are different, the obtained results are comparable to the best results for RT cw operation in this wavelength range, e.g., $\sim 100 \mathrm{~mW}$ (Refs. 14 and 15) at $9.5 \mu \mathrm{m}$ with a HR coating. The same device operated in pulsed mode with $1 \%$ duty cycle has a peak output power of $360 \mathrm{~mW}$ for one facet and a threshold current density of $1.22 \mathrm{kA} / \mathrm{cm}^{2}$ at $300 \mathrm{~K}$. The inset in Fig. 3 shows the emission spectra of the same device at various currents from threshold to the roll-over current at $300 \mathrm{~K}$.

In conclusion, we demonstrated high performance RT $\lambda \sim 9 \mu \mathrm{m}$ QCLs based on a three-phonon-resonance

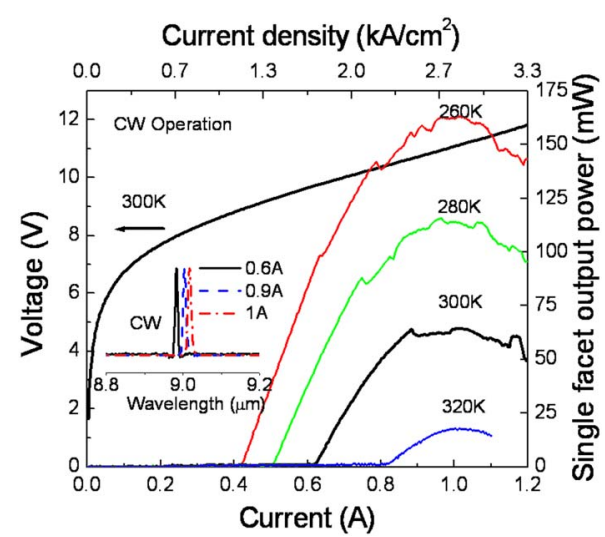

FIG. 3. (Color online) Light output power vs current $(L-I)$ and voltage vs current $(V-I) \mathrm{cw}$ curves of a laser device without HR coating at temperature between 260 and $320 \mathrm{~K}$. The cavity length is $3 \mathrm{~mm}$ and the ridge width is $12 \mu \mathrm{m}$. The device was epilayer down mounted on an AlN submount, then on a copper plate with indium. The whole copper plate was then indium bonded on a copper block and thermally controlled with a TE cooler. The measured power was not corrected for an estimated $70 \%$ collection efficiency of the setup. The inset shows cw spectra as a function of injection current measured with the same device at a constant temperature of $300 \mathrm{~K}$.

scheme. It is expected that a better cw performance of the device can be achieved with improved processing, such as adopting a planarized regrown semi-insulating InP layer, and an improved packaging.

Part of the processing work was performed at the Center for Nanoscale Systems (CNS), a member of the National Nanotechnology Infrastructure Network (NNIN), which is supported by the National Science Foundation under NSF Award No. ECS-0335765.

${ }^{1}$ J. Faist, F. Capasso, D. L. Sivco, A. L. Hutchinson, and A. Y. Cho, Science 264, 553 (1994).

${ }^{2}$ A. Lyakh, C. Pflügl, L. Diehl, Q. J. Wang, F. Capasso, X. J. Wang, J. Y. Fan, T. Tanbun-Ek, R. Maulini, A. Tsekoun, R. Go, and C. K. N. Patel, Appl. Phys. Lett. 92, 111110 (2008).

${ }^{3}$ Y. Bai, S. Slivken, S. R. Darvish, and M. Razeghi, Appl. Phys. Lett. 93, 021103 (2008).

${ }^{4}$ L. Diehl, D. Bour, S. Corzine, J. Zhu, G. Hofler, M. Loncar, M. Troccoli, and F. Capasso, Appl. Phys. Lett. 88, 201115 (2006).

${ }^{5}$ S. Slivken, A. Evans, W. Zhang, and M. Razeghi, Appl. Phys. Lett. 90, 151115 (2007).

${ }^{6}$ M. Beck, D. Hofstetter, T. Aellen, J. Faist, U. Oesterle, M. Ilegems, E. Gini, and H. Melchior, Science 295, 301 (2002).

${ }^{7}$ J. Faist, M. Beck, T. Aellen, and E. Gini, Appl. Phys. Lett. 78, 147 (2001).

${ }^{8}$ A. Tredicucci, F. Capasso, C. Gmachl, D. Sivco, A. Hutchinson, and A. Cho, Appl. Phys. Lett. 73, 2101 (1998).

${ }^{9}$ K. Fujita, S. Furuta, A. Sugiyama, T. Ochiai, T. Edamura, N. Akikusa, M. Yamanishi, and H. Kan, Appl. Phys. Lett. 91, 141121 (2007).

${ }^{10}$ S. Blaser, L. Diehl, M. Beck, J. Faist, U. Oesterle, J. Xu, S. Barbieri, and F. Beltram, IEEE J. Quantum Electron. 37, 448 (2001).

${ }^{11}$ J. Faist, D. Hofstetter, M. Beck, T. Aellen, M. Rochat, and S. Blaser, IEEE J. Quantum Electron. 38, 533 (2002).

${ }^{12}$ D. Hofstetter, M. Beck, T. Aellen, and J. Faist, Appl. Phys. Lett. 78, 396 (2001)

${ }^{13}$ C. Faugeras, S. Forget, E. B. Duchemin, H. Page, J. Y. Bengloan, O. Parillaud, M. Calligaro, C. Sirtori, M. Giovannini, and J. Faist, IEEE J. Quantum Electron. 41, 1430 (2005).

${ }^{14}$ J. S. Yu, S. Slivken, A. Evans, S. R. Darvish, J. Nguyen, and M. Razeghi, Appl. Phys. Lett. 88, 091113 (2006).

${ }^{15}$ C. Pflügl, L. Diehl, A. Tsekoun, R. Go, C. K. N. Patel, X. Wang, J. Fan, T. Tanbun-Ek, and F. Capasso, Electron. Lett. 43, 20072162 (2007). 